\title{
Relevance and Relationalism
}

\author{
Mark Young
}

Published online: 25 February 2011

(C) The Author(s) 2011. This article is published with open access at Springerlink.com

\begin{abstract}
This paper will provide support for relationalism; the claim that the identity of objects is constituted by the totality of their relations to other things in the world. I will consider how Kit Fine's criticisms of essentialism within modal logic not only highlight the inability of modal logic to account for essential properties but also arouse suspicion surrounding the possibility of nonrelational properties. I will claim that Fine's criticisms, together with concerns surrounding Hempel's paradox, show that it is not possible to provide a satisfactory account of certain properties in abstraction from their place within a wider context. Next, we will shift attention to natural kinds and consider the notion that relevance plays in metaphysical accounts of identity, by examining Peter Geach's notion of relative identity. I will argue that the intensional relation between subject and object must be included in a satisfactory account of metaphysical identity.
\end{abstract}

Keywords Relevance $\cdot$ Relationalism $\cdot$ Holism $\cdot$ Anti-essentialism

The aim of this paper will be to provide support for a form of ontological holism that fills the vacuum in analytic philosophy, namely the "relationality thesis." Versions of this thesis can be found in the early work of Heidegger, ${ }^{1}$ and throughout the work of Richard Rorty. For the purposes of this essay, we will take the relationality thesis to be the claim that the identity of objects is constituted by the totality of their relations to other things in the world. Due to its insistence that identity is constituted by all of the relations an object shares with the world, this thesis can be understood to be holistic.

I will provide support for this thesis by arguing that the notion of nonrelational properties is fundamentally incoherent, thereby providing a criticism of the doctrine of essentialism. The metaphysical consequences of such a theory are not to be

\footnotetext{
${ }^{1}$ See Weberman n. d. and Rorty 1999.

M. Young $(\bowtie)$

Department of Philosophy, Faculty of Humanities, University of Bergen, Bergen, Norway

e-mail: Mark.Young@student.uib.no
} 
underestimated, for if we accept (as I believe we are compelled to) that the total set of relations that an object shares with the world to be constantly changing, then the project of forming a static account of metaphysical identity that persists through time is severely compromised. Yet, if we can finally manage to part ways with our platonic heritage, and allow what changes to also be considered as real, we may find that many classic and modern philosophical problems concerning identity lose their significance.

I will begin this paper by considering how a traditional ontological distinction, that between essence and accident, has hindered the development of ontological forms of holism. I will then present a criticism of the notion of nonrelational properties that are the cornerstone of theories of essentialism in two parts:

Firstly, I will consider how the criticisms leveled by Kit Fine toward conceptions of essentialism within modal logic work not only to elucidate the inability of modal logic to account for essential properties but also work to arouse suspicion surrounding the possibility of nonrelational properties. I will claim that Fine's criticisms, together with concerns surrounding Hempel's paradox, expose an incoherence in the notion that it is possible to provide a satisfactory account of certain properties in abstraction from their place within a wider context.

Secondly, we will shift our attention to essentialism in natural kinds and consider the notion that relevance plays in metaphysical accounts of identity, by examining Peter Geach's notion of relative identity. I will argue that the intensional relation between subject and object must be included in a satisfactory account of metaphysical identity.

It is my view that these two relations: that between a property and the environment in which it exists, and that between a subject and an object must be included in any satisfactory account of metaphysical identity. Such an inclusion would severely compromise the notion of nonrelational properties, thereby challenging the plausibility of the doctrine of essentialism.

\section{Ontological Holism in Analytic Philosophy}

In Holism and Analytic Philosophy, Micheal Esfeld argues that a satisfactory conception of holism "should construe holism in the first place as an ontological claim" (Esfeld 1998), a demand that is voiced with increasing insistence by those who wish to foster increased cooperation between philosophy and certain areas of modern science. That such a demand should have to be made is in itself puzzling, for very few areas of philosophy have experienced such a focus on holistic ideas as analytic philosophy, in which we have seen epistemological and semantic holism espoused in a number of seminal works. However, it is often overlooked that theses "such as the Duhem-Quine thesis or coherentism, can be construed as ontological claims too: they are claims about necessary conditions under which certain entities have certain properties." 2 To hold that such holistic claims can apply only to language or to knowledge is to subscribe to a certain conception of the way in which

\footnotetext{
${ }^{2}$ Ibid, p. 366
} 
language and the world are related: a conception which isolates scheme and content from one another. However, if we are to accept Sellar's slogan that "all awareness is a linguistic affair" and side with philosophers like Rorty and Davidson ${ }^{3}$ who have worked to transcend such traditional philosophical distinctions as that between scheme and content, we find that epistemological and semantic holism are not content to find application only within the boundaries of knowledge and language but demand application also within ontology.

So, why is it so difficult to find an analog to the epistemological and semantic holism that applies to ontology within the annals of analytic philosophy? I believe that the lack of interest can be explained by reference to the popularity of a certain traditional distinction involved in the analysis of metaphysical identity that we have inherited from the philosophy of early Greece. The distinction between essence and accident forms a cornerstone of metaphysics because it concerns the identity of objects in the world. Quine summarized the essentialist doctrine as "the doctrine that some of the attributes of a thing (quite independently of the language in which the thing is referred to, if at all) may be essential to the thing and others accidental. E.g., a man, or talking animal, or featherless biped (for they are all the same thing) is essentially rational and accidentally two legged and talkative, not merely qua man but qua itself" (Quine 1966). Despite the controversy surrounding his claim that this is the Aristotelian form of the doctrine, it is sufficient for our purposes. Its importance in the history of philosophy has led to two major endeavors that have attempted to clarify and systematize these concepts.

Firstly, essence has been compared to a definition. It was assumed that the method of specifying the identity of a word could also be applied to objects in terms of identifying which properties were essential and which were accidental. This method, while popular throughout the history of philosophy, has largely fallen into disrepute in modern analytic philosophy, possibly due to the difficulties created by Quine's semantic holism thesis which denied the possibility of isolating propositions from the language in which they are stated while still retaining their meaning.

Secondly, essence has been translated into modal terms in which essence is equated with necessity. We can say therefore that an object "de re" necessarily possesses a quality which can be interpreted as the claim that the possession of the property in question is essential to the identity of that object. This method was a "late bloomer" and did not find concise explication in the works of ancient Greek philosophers, but has however received increasing attention throughout the history of philosophy consistently up to the present day, and now represents the most acceptable framework within philosophy that a discussion of essential properties can take place.

So, why does a distinction between essence and accident hinder the formation of a thesis of ontological holism? Because to claim that a certain section of the totality of properties an entity possesses ${ }^{4}$ constitutes the identity of that entity is also to claim

\footnotetext{
${ }^{3}$ For an account of holism in Davidson's work, see (Malpas 1992)

${ }^{4}$ The essentialist claim is not restricted to properties and has been formulated recently concerning a number of features, such as functions, dispositions, and causal powers.
} 
that it is possible to abstract that entity from some part of its particular temporal and physical environment while still retaining its identity, ${ }^{5}$ which is precisely what is prohibited by holistic theories. We can see clearly the incongruence that exists between the relationality thesis and essentialism in their attempts to explicate identity; relationalism insists that everything confers identity to an object, while essentialism insists with just as much vigor that identity conferring relations or properties must be restricted. ${ }^{6}$ The essentialist claim should ring familiar as a form of reductionism, for it is no coincidence that the essential accidental distinction was among the doctrines selected from the peripatetic tradition for canonization by seventeenth century corpuscularians. The intuition that what changes could not be real was further reinforced by what Ken Wilbur has called the "principle of measurement" in which during the seventeenth century, the analysis of nature shifted from Aristotelian classification to measurement, leading to a widespread intuition that what could not be quantified was existentially inferior (Wilber 1977).

\section{Essentialism and Modal Logic}

In the twentieth century, Saul Kripke developed a system of modal logic in which debates concerning essentialism were revived. After Quine, it became common to claim that "It is built into our very understanding of de re metaphysical necessity that certain descriptions, as opposed to others will be regarded as revealing the essence of the object" (Fine 2005). In Essence and Modality, Kit Fine argues against the assimilation of the notion of essence to metaphysical necessity. These criticisms form part of a greater philosophical project for Fine, in which he encourages a return to definitional accounts of essence. Fine notes an asymmetry to exist between notions of necessary and essential attributes, claiming that all essential properties are necessary properties, but not all necessary properties are essential properties. Necessary properties are therefore only sufficient and not necessary for the status of essential properties and therefore should not be regarded as synonymous. Conducting an analysis of the metaphysics of identity as part of a wider application of modality de re in applied logic thus is fundamentally flawed, because such a system cannot make the distinction between necessary properties and those necessary for an essentialist ontology.

The relevance of such a claim to a relationalist ontology is revealed with the help of an example. It is necessary to an apple in New Zealand that it be distinct from a

\footnotetext{
${ }^{5}$ In the Aristotelian form of essentialism, the claim involves a particular kind of abstraction. In the Metaphysics, Aristotle does not claim that primary being (essence) can exist separately from the universals that characterize them, and criticizes Plato for supporting such a claim. He does, however, claim that the particular combination of accidental properties an entity possesses do nothing to confer ontological identity. This is the kind of abstraction that is criticized in this paper: an abstraction of identity and not existence.

${ }^{6}$ It is important to note that essential properties must have a complement; that is, the notion of essential properties is a distinction that must be drawn among properties, to segregate some from others. If we take all the properties of an object to be essential, the essentialism thesis collapses into the relationality thesis outlined above. Vasilis Politis states "For if a thing has as many essences as it has properties, then we can forget about the concept of essence altogether, and we need only retain the general concept of a property" (Politis 2004).
} 
coffee cup which is sitting on a table in a small café in Egypt. But it is not essential to the apple that it be distinct from the cup, for as Fine claims, there is nothing in the apples nature that connects it in any way with the cup (Fine 1994). Fine regards this as showing the inadequacies of modal logic in coping with the essentialist doctrine, in a moment of sarcastic eloquence he states "oh happy metaphysician! For in discovering the nature of but one thing, he thereby discovers the nature of all things." 7

This idea should strike the reader as familiar, for in failing to restrict the attribution of essential properties in a way which corresponds to our intuitive notion of essence, it succeeds in articulating the relationality thesis. Fine regards the above example as illuminating the inability of modal logic to account for essentialism. I want to suggest instead that the incoherence of the essentialist doctrine is exposed in its translation into modal terms. And that the burden of proof lies with essentialism in demonstrating its value as a necessary ontological thesis.

And why not? That the identity of the apple is related to the identity of the cup in some way is a claim that has found limited articulation in philosophy despite its status as heresy within the western philosophical tradition and counterintuitive nature. We find this idea for example in Hegel's Science of Logic in which he claims that "a finite being is one that relates itself to something else; it is a content which necessarily stands in relation to other content, to the whole world" (Hegel 1989). Here, Hegel argues that an object of thought that is anything less than the totality of existence is finite and is actively limited by anything which falls outside the boundaries of its being. Applied to the above example, we could say that the cup plays a role in limiting the identity of the apple and stands therefore in a necessary relation to it.

It was in response to such ideas that G.E. Moore formulated his famous criticism of the doctrine of internal relations early in the twentieth century. Moore translated essentialism into informal modal terms - "x might have existed without a certain property," and thereby missed the subtleties concerning identity and existence. The consequences such a claim holds hang entirely upon our understanding of how $\mathrm{x}$ is claimed to exist in the absence of certain attributes. For if we allow (as I think we must) that $\mathrm{x}$ would exist differently due to the absence or acquisition of properties - that without fathering George V, Edward VII would have been different - then the affirmation of such a claim does not support an essentialist doctrine.

I am therefore supporting a far stronger thesis of relationalism than that which Moore set out to refute in his seminal paper "Internal and External Relations." Moore's argument highlights what he takes to be the central claim of the doctrine of internal relations - that all relations modify the terms involved. Yet, his analysis of this doctrine functions by reducing entities into terms and relations, thereby betraying its own essentialist foundations and begging the question. For in asking, whether or not a relation modifies its terms is to have already subscribed to a particular metaphysical account of the identity of objects, one which allows for the discussion of entities in isolation from their environment. A similar argument has been employed by Hubert Dreyfus to demonstrate the incoherence of Satosi

\footnotetext{
${ }^{7}$ Ibid.
} 
Watanabe's notion of quantifying value in artificial intelligence projects. ${ }^{8}$ The problem with both Moore and Watanabe's approach is that relations and values are taken to represent determinations which can be added or subtracted from already existent objects. The idea that such determinations somehow play no role in the determination of these objects is what the thesis of relationalism brings into question, and following Hubert Dreyfus, I will argue that the solution can only be provided by modifying the way in which we pose the question. Changing vocabulary is sometimes necessary to make progress with old problems; Rorty, for example, writes that "Interesting philosophy is rarely an examination of the pros and cons of a thesis. Usually it is, implicitly or explicitly, a contest between an entrenched vocabulary which has become a nuisance and a half formed new vocabulary which vaguely promises great things" (Rorty 1989).

The difference between essential properties and necessary properties has been noticed before, by the two philosophers jointly responsible for the doctrine of essence-Plato and Aristotle. In Plato's Euthyphro for example, it is claimed that things that are good are necessarily desired by the gods, and things that are necessarily desired by the gods are good, yet the essence of such objects is that they are good and not that they are desired by gods. Plato held that "a two way necessary relation between things is compatible with a one way essential relation between them" (Politis 2004).

The problem for modal logic in articulating the essentialist doctrine can be summarized briefly by stating that an essential property is nonrelational and that necessary properties can be relational. It seems that for any object, we could generate a large number of trivial and arbitrary necessary truths that involve relations. The number of arbitrary necessary truths that it is possible to generate for one object is limited only by the number of beings and properties that we allow to populate our ontological universe.

This problem runs deep; not only does it show that necessity and essence are not extensionally equivalent, it also shows us that in a sense, all properties can be considered relational. We understand accidental properties to be relative - the greenness of grass is a property which is claimed to depend on the constitution of a perceiving subject and the chemical constitution of the object. But even if we take a property that is commonly held to be both essential and necessary such as the atomic number of hydrogen, we could supply negative claims of necessity such as "it is necessary that hydrogen does not have the atomic number of 2 " to counter the positive claim that "it is necessary that hydrogen has the atomic number of 1 ." We could combine such negative identity claims to provide one that is logically equivalent to the single positive claim. Such a claim would appear as "All atomic elements that do not have the atomic number of 1 are not hydrogen." Karl Hempel used such a claim to provide the foundations for an instantial theory of inductive method that many have found to hold counterintuitive consequences. The "equivalence principle" states that "If $e$ is confirming evidence for hypothesis 1, and hypothesis 1 is logically equivalent to hypothesis 2 , then $e$ is confirming

\footnotetext{
8 "Although talk of values is rather new in philosophy, it represents a final stage of objectification in which the pragmatic considerations which pervade experience and determine what counts as an object are conceived of as just further characteristics of independent objects, such as hardness and color" (Dreyfus 1972).
} 
evidence for hypothesis 2" (Sosa and Dancy 1993). According to this principle, a yellow banana provides evidence for the claim that all eggplants are purple. This theory has been subject to heavy criticism, most notably over the limited structure of claims that appear within it (all As are Bs) and concerning the issue of observation. However, such a theory does bring the notion of nonrelational properties into question. For if our investigations into the identity of an object depend to some extent on evidence instantiated in other objects, must we not allow that identity itself is relational? Without the existence of a plethora of different atomic elements, each with different atomic numbers, hydrogen could not be said to possess a property of having a single proton. And this is not because perceiving subjects could not notice such a property, but because as Hegel claimed, a property is constituted by its differentiation from a totality. A property that everything possesses and nothing can lose does not seem like a property at all; following Kant, we could claim that "existence is not a predicate." This casts doubt on the possibility of considering properties in isolation and encourages us to understand all properties as relying on relations to other properties for their determination.

But there is another problem with the instantial model of induction that Hempel advocated, and one that bears uncanny similarity to Fine's criticism of equating essence to necessity. For a yellow banana not only provides evidence that all eggplants are purple, but also that all eggplants are white. It seems that this model of induction allows an instance of anything to stand as evidence for a claim of nearly anything. Hempel's inductive method faces the same problem that modal logic faces with the essentialist doctrine; both seem unable to restrict their results in a way that corresponds to our intuitions. The notion of background information that we use to restrict our inductive investigations has been proposed as a solution for Hempel's instantial theory; it is this information that determines the relevance of evidential instances to a particular hypotheses. Reflecting on the difficulties modal logic faces in articulating essentialism, Kit Fine also notes that what is required is a condition of relevance, but notes that such an addition would provide no solution because "it is hard to see how the required notion of relevance could be understood without already presupposing the concept of essence in question," concluding that "there is nothing in the 'logic' of essence to justify an asymmetric judgment of relevance" (Fine 1994).

The notion of relevance occupies a crucial position in theories of identity, and can be construed in different ways. Undoubtedly, Fine regards relevance in the above passages as pertaining to a notion of absolute identity such that would occur within a realist ontology. For example, within Locke's framework of primary and secondary qualities, we could anticipate a claim that quantifiable properties such as length are more relevant to the identity of an object than sensible properties such as color.

It seems that the notion of relevance bears more than a striking similarity to the notion of essence. Only a proportion of properties can be relevant to the identity of an entity, if we take all properties to be relevant the meaning of the notion collapses. Indeed, properties we take to be essential are therefore relevant, and properties are relevant because they are essential. Relevance in the sense that Fine applies the term is therefore extensionally equivalent to essence.

The notion of relevance has also proved to be the stumbling block for classical artificial intelligence projects founded upon propositional representations of the 
external world. The intractability of the "frame problem" highlights how the failure to add structures of relevance to already formed symbolic maps of the world in the effort to facilitate pattern recognition represents a theoretical problem and not merely a limit posed by the current state of technology. Dreyfus draws attention to the fact that for a program to recognize something as an eye, it must have already recognized the context as a face, and that "if each context can be recognized only in terms of features selected as relevant and interpreted in terms of a broader context, the AI worker is faced with a regress of contexts" Dreyfus (1972). The "frame problem" displays how relevance cannot be formalized and, in doing so, highlights the thesis of this paper-that relevance permeates our world at a fundamental level and therefore resists abstraction.

Relevance can be construed in a number of different ways depending on the goals that we employ in seeking to classify an object. It is relevance that forms a bond between subjects and objects, a relation that I will argue no satisfactory account of identity can do without. It is this idea that I will explore in the next section, marking our departure from Kit Fine and turning our attention toward the notion of natural and artificial kinds.

\section{Relevance and Relativity in the Metaphysics of Identity}

Imagine a man whose job is to wade through garbage heaps and group together objects that weighed over $50 \mathrm{~g}$ and objects that weighed under $50 \mathrm{~g}$. Like any normal garbage heap, there exists a huge variety of objects, from cans to empty potato chip bags, and consequently, each group of objects comes to include objects of different materials, weights, and volumes. Eventually, for ease of communication when explaining to his employer which pile was which, both came to refer to the two classes of objects as the "over 50s" and the "under 50s," respectively.

Following the tradition of distinguishing between primary and secondary qualities, we could claim that the weight of objects is the primary quality of these two classes of objects, and is not related to us in any way. We could claim that this is an unproblematic example of a nonrelational property (or a self-relational property as Aristotle asserted as fundamental to his conception of essence); the weight of the objects would have been the same regardless of whether they had been weighed and classified. Although I believe that modern physics has presented serious challenges to the notion of primary properties, ${ }^{9}$ I am going to allow for the sake of argument that such properties could exist, in order to illustrate that the relationships between subject and object must be included in any satisfactory account of metaphysical identity.

So, when questioned about the identity of the two classes of objects, the man may be inclined to say that "possessing a weight greater than $50 \mathrm{~g}$ " is an essential quality for the over $50 \mathrm{~s}$, whereas the material of which each object is constituted (plastic, metal, etc.) is merely an accidental property.

\footnotetext{
${ }^{9}$ While the incompatibility of Quantum Mechanics and Relativity theory bewilders those who work towards a grand unification, the challenge that these two theories pose to the present discussion is curiously similar: how can we include frames of reference in our descriptions of an independent world?
} 
What are we then to say about the class of "under 50s"? Does it represent a natural or an artificial kind? The criterion of identity for this class of objects is weight, a measurable quality commonly taken to be nonrelational. However, the act of classification itself is related to the owner of the garbage heap, and his desire to implement a certain system. His selection of certain properties, and not others, reflects our intuition that in this case, identity is theory-relative.

The intuitive response here I think is that "under 50s" is an artificial kind, because the existence of this class depends on the goal-directed activity of people, even though the property, which determines class membership, can be assumed not to depend on human interaction. Yet, adopting this view creates problems for the notion of natural kinds. For classification itself is a goal-directed activity and involves the adoption of a particular intensional stance toward an object. It is the intensional stance, necessary to all acts of classification that form a relationship between observer and object, and renders the notion of nonrelational properties extremely problematic.

Now, it could be replied that obviously, all objects in the world stand in certain relations, and that the properties of objects also stand in relations to observers. Yet, concerning the weight of an object, the intensional relationship that this property forms with observers constitutes nothing of the character of the property. We could say that our perceptual relation with the weight of an object is accidental. But by shifting the division of relations into accidental and essential from the level of object to properties provides no remedy to the problems inherent in an empiricist account of essence, for we cannot help but become embroiled in an infinite regress of divisions, shifting deeper into experience but never grasping that which we seek.

One might wonder how a nonrelational property could become a criterion for an essentialist definition of identity within empiricism in the first place. A strictly empiricist conception of identity prohibits in its methodology alone the existence of true nonrelational properties, because any property always stands in some relation to observers. We could say that true nonrelational properties died when Robert Boyle espoused the empirical restraint which would become a cornerstone of the scientific revolution - that "the essence of a thing must be selected from among its sensible attributes" (Kultgen 1956). In effect, what Boyle demanded was that we select nonrelational properties from relational properties, and we need not be established logicians to appreciate the futility of this notion.

That all acts of classification must occur within some intensional framework is an idea that has found expression in both the continental and analytic tradition during the twentieth century; Kant's notion of apperception and Heidegger's claim that "The 'as' makes up the structure of the explicitness of something which is understood" (Heidegger 1962) complement the same notion expressed in Rorty's denial of the existence of a "skyhook." The increased popularity of such arguments in modern philosophy explains the disappearance of claims of "presuppositionless" methods in both continental and analytic philosophy. And neither can we claim that the nature of the goals which direct our enquiry can help us to demarcate the difference between natural and artificial kinds, for as both Rorty and Heidegger claim that there is no "natural" frame of enquiry or set of goals with which we could support such a claim. To see the way in which classification is an active goal-directed enterprise, let us consider water. Perhaps due to Putnam's "twin earth" thought experiment which he wielded in defense of natural kind essentialism, water is often thought to be a good 
candidate for natural kinds in philosophical debates concerning essentialism. However, water is far more complex than some would like to allow. Water $\left(\mathrm{H}_{2} \mathrm{O}\right)$ and heavy water $\left(\mathrm{D}_{2} \mathrm{O}\right)$ represent water molecules containing two different isotopes of hydrogen. Isotopes of an element all contain the same number if protons and electrons, yet differ in the number of neutrons and also therefore atomic mass. Concerning properties, however, water and heavy water are the same molecule in terms of solubility, but different in terms of boiling points (where atomic weight is the relevant factor). Such cases suggest that what counts as an intrinsic or primary quality of an object depends upon exactly what behavior we are seeking to investigate. ${ }^{10}$ Yet, the notion of relevance to our interests holds no place within a doctrine of essences, which seeks to insulate part of reality from the effects of observers.

The notion of natural kinds finds articulation within a framework that separates subject from object. It assumes the possibility of passively receiving information about the world with which we can establish claims about the nature of an object which is not related to our classificatory actions. It is therefore understood that activity on the part of the subject compromises our claims to objective knowledge, because such knowledge is defined precisely by its independence from all perceiving subjects. We find ourselves then in a curious situation: seeking to actively characterize the nature of external reality while remaining as passive as possible throughout the process. ${ }^{11}$ The full significance of this problem is revealed in historical accounts of the development of quantum mechanics. In investigating the behavior of subatomic particles, physicists in the early part of the twentieth century encountered a problem that exposed a fundamental flaw in the notion of an "external" world. Put simply, the smallest possible instrument (a photon) with which we could use to gather information of certain subatomic particles would disturb them in such a way as to make it impossible to collect the data. The act of measurement could no longer be perceived as a passive reception of information, the instrument no longer understood to be a mere extension of our sensory capacities, even the boundaries between subject and object were called into question. Ken Wilbur states that "objective measurement and verification could no longer be the mark of absolute reality, because the measured object could never be completely separated from the measuring subject-the measured and the measurer, the verified and the verifier, at this level are one and the same" (Wilber 1977).

The contradictory element underlying our claim that it is possible to gain knowledge of an "external" reality is implicit in Carnap's Empiricism, Semantics and Ontology in which he asserts that our claims to knowledge are only meaningful if posed within a certain linguistic framework. Carnap claims that "To be real in the scientific sense means to be an element of the system; hence this concept cannot be meaningfully applied to the system itself" (Carnap 1966). Claims to knowledge of a world independent of us are analogous to such external questions, and not only are they meaningless, but also downright contradictory.

\footnotetext{
${ }^{10}$ The decision concerning whether or not to regard isotopes as elements was subject to much debate within the scientific community. Despite the ruling that isotopes are to be considered as forms of the elements of which they share the same number of protons, the controversy continues to this day.

${ }^{11}$ Hegel noted this peculiarity in Phenomenology of Spirit forming from it a point of criticism of the form of consciousness of sense perception- "In apprehending it, we must refrain from trying to comprehend it" Krasnoff (2008).
} 
The relation between objects and the classificatory activity of subjects was formalized in the work of English philosopher and logician Peter Geach, who advocated a logic of identity that rejected the notion of absolute identity. It is interesting to note that Geach shares his motivation in proposing such an account with centuries of scholastic philosophy before him, to explain the paradoxical nature of identity in the holy trinity. Such a concern led Geach to propose that the claim that " $x$ is identical with $y$ " is "an incomplete expression; it is short for " $x$ is the same $A$ as $y$ ' where ' $A$ ' represents some count noun understood from the context of utterance" (Geach 1967). Geach argues that our ontology is related in a fundamental way to our ideology, and an identity theory based on either identity predicates or quantification must allow for this relativism. Geach is concerned to show that different theories construe identity in different ways according to the particular kinds of predicates they employ, and that we risk Meinongian exponential growth of our ontology if we continue to voice a commitment to a notion of absolute identity. Quine's solution of an interpretation of quantifiers that yields absolute identity by preserving truth conditions between the same proposition interpreted in different theories is admitted by Geach to work, but is rejected on the grounds that it does not grant our ideologies the appropriate flexibility without drastically altering our ontology. By relinquishing the notion of absolute identity, Geach argues, we create distance between ontology and ideology, granting the latter the flexibility we require it to have. In considering the overgrown jungle that our ontology could become, Geach remarks "We surely need Ockhams razor to cut through this tangle; and it is not too hard to see where to make the cut. We reject absolute identity, but admit as many as we need of two place predicables of the form '- is the same $A$ as -' where ' $A$ ' is some count noun." 12 Such an argument claims that the relation between theory and identity is not to be ignored, and if we understand theory in terms of human activity as Rorty would suggest, ${ }^{13}$ the notion of a world that is truly independent of us is no longer feasible.

I believe the notion of nonrelational properties which underlies the essentialist doctrine to be an anachronism, a remnant of an outdated system of thought that has somehow remained unnoticed like a stowaway in the bowels of a ship. Within a teleological cosmology, a notion of identity that is truly independent of us and its environment is unproblematic, because it has been bestowed upon objects in terms of form and purpose. As far as I know, there are no philosophical debates concerning the "true" identity of can openers and television sets. Asking for "absolute identity" in a secular framework is tantamount to posing a teleological question from outside Carnap's teleological framework.

But should we sympathize with Aristotle, in regarding the notion of natural kinds to possess not only explanatory value but utility too? ${ }^{14}$

\footnotetext{
${ }^{12}$ Ibid p. 10

${ }^{13}$ Rorty puts it succinctly in claiming that "we should think of language not as naming a thing with an intrinsic nature of its own, but as a way of abbreviating the kinds of complicated interactions with the rest of the universe that are unique to the higher anthropods." From (Rorty 1999)

${ }^{14}$ Aristotle seemed to contradict himself on this point, for he argued that essentialism is necessary for thought and language to function, but at the same time maintained that episteme (the mode of explanatory knowledge of which natural kinds belong) is characterized as knowledge for the sake of leisurely contemplation. Goal directed activity belongs more to techne, which was held by Aristotle to be inferior to episteme.
} 
We can respond to this objection simply by stating that we can be certain about some things, that the next hydrogen atom will have only one proton, or that the carton of milk in my fridge will not change overnight into an eggplant for example, without that certainty featuring in our ontology as an entity of a particular kind. If we trade certainty for essence, we remove one more obstruction to a plausible account of ontological holism. Such an account must recognize the two forms of relations discussed above as fundamental in its conception of ontological identity, that between objects and objects, and that between objects and subjects. For in doing so, we pave the way for a thesis of relationalism in which we recognize that "there are relations all the way down, all the way up, and all the way out in every direction; you never reach something which is not just one more nexus of relations" (Rorty 1999).

Open Access This article is distributed under the terms of the Creative Commons Attribution Noncommercial License which permits any noncommercial use, distribution, and reproduction in any medium, provided the original author(s) and source are credited.

\section{References}

Carnap, Rudolf. Empiricism Semantics and Ontology cited from Ayer, A.J (edts) Logical Positivism The Free Press, (U.S.A 1966)

Dreyfus, L. Hubert. What Computers Still Can't Do: A Critique of Artificial Reason M.I.T University Press (U.S.A 1972)

Esfeld, Michael. Holism and Analytic Philosophy Mind, Vol. 107. 426. April 1998 (Oxford University Press 1998)

Fine, Kit. Essence and Modality cited from Philosophical Perspectives 8: 1-16 (1994)

Fine, Kit. Modality and Tense; Philosophical Papers Oxford University Press, New York (U.S.A 2005)

Geach, P.T. Identity from The Review of Metaphysics Vol.21, No.1 (September 1967) pp3-12 Philosophy Education Society Inc

Hegel, Georg. Hegel's Science of Logic Miller, Arthur (trans) Prometheus Books (U.S.A 1989) 1:71

Heidegger, Martin. Being and Time Macquarrie, John and Robinson, Edward (trans) Basil Blackwell (U.K 1962)

Krasnoff, Larry. Hegel's Phenomenology of Spirit: An Introduction Cambridge University Press, New York (U.S.A 2008)

Kultgen, J.H. Boyle's Metaphysic of Science from Philosophy of Science Vol.23 No.2 (April 1956) pp136141 University Chicago Press

Malpas, J.E. Davidson and the Mirror of Meaning: holism, truth, interpretation University of Cambridge Press (U.K 1992)

Politis, Vasilis. Routledge Guidebook to Aristotle and the Metaphysics Routledge, New York (U.S.A 2004)

Quine, W.V. "Three Grades of Modal Involvement" The Ways of Paradox, New York; Random House, (U. S.A 1966)

Rorty, Richard. Contingency, Irony and Solidarity University of Cambridge Press, Cambridge (U.S.A 1989) p9

Rorty, Richard. A World without Substances or Essences from Philosophy and Social Hope Penguin Books (U.K 1999)

Sosa, Enerst and Dancy, Jonathon. A Companion to Epistemology Blackwell Publishing (U.S.A 1993) p410

Weberman, David. Heidegger's Relationalism, British Journal for the History of Philosophy, 9: 1, 109122

Wilber, Ken. The Spectrum of Consciousness Quest Book printing, Illinois (U.S.A 1977) 